\title{
Micro-cracks detection in Photo-Voltaic Cells by Infrared Thermography
}

\author{
by L. St-Laurent, M. Genest, C. Simon, X. Maldague
}

Electrical and Computing Engineering Department

Université Laval, Quebec City (Quebec) Canada G1K 7P4

ph: (418) 656-2962, fax: (418) 656-3594, E-mail: maldagx@gel.ulaval.ca

\begin{abstract}
In this paper, a technique is presented to detect micro-cracks on photo-voltaic cells by infrared thermography. The originality of the system comes from the thermoelectric stimulation used to generate thermal transients at micro-crack locations. These thermal transient are picked-up by an infrared cameras for further detection.
\end{abstract}

\section{Introduction}

With the recent Canadian signature of the Kyoto protocol on greenhouse gas reduction, renewed interest for green Photo-Voltaic (PV) electrical energy generation is noticed. For instance, some countries are tax waiving PV modules as incentives for consumers (e.g. Belgium, soon Canada among others). PV modules manufacturers are thus faced with an increased demand. With less time for manual inspection, automatic inspection of PV modules is preferred. In addition to traditional electrical tests, new methods are looked for to detect and locate defects within PV cells themselves. Of importance is crack detection which can lead to total dysfunction of PV modules if micro-cracks degenerate into open cracks preventing the photo-current to be collected at PV cell output [1-4].

In mono and polycrystalline silicon PV cells, micro-cracks are generally induced by mechanical cutting of individual cells from larger silicon ingots. These are so tiny that visual detection is not really practical, especially at high production cadence. In fact, detection is so hard that it is even very difficult to get specimens of PV cells with micro-cracks!

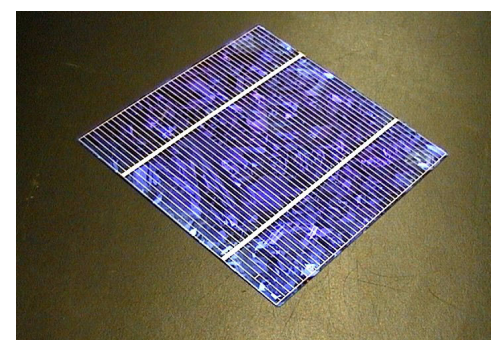

Fig. 1: Visible picture of a cracked solar cell. 


\section{http://dx.doi.org/10.21611/qirt.2004.081}

\section{Introduction}

Among different techniques of non-destructive testing available [5], Infrared thermography (IRT) is seen as a promising technique to detect (micro-)cracks. However, up to now, no authors has demonstrated a practical technique to perform such a task [6-8]. In fact a survey of the literature shows that generally authors rely on the following techniques to generate significative temperature differences in PV cells (these temperature differences are later detected by an IR camera pointed out to the thermally stimulated PV cells): • heat generated and detected following application of electrical power at PV electrodes, heat generated by radiative (lamp heating) or convective (air blowing) techniques. Either transient or modulated schemes were tested with various degree of success. In fact: radiative techniques revealed not appropriate due to the high reflection of the PV cell coating that prevents efficient heating. Convective approaches are better.

In the current project, deployment of IRT was studied for automatic microcrack detection. The approach selected was conductive thermoelectric stimulation.

\section{Theory}

For the detection of surface cracks, a practical way to proceed consists to have the thermal front propagating along the surface, this is known as lateral surface heating). This takes advantage of the thermal resistance at the interface created by the crack (especially in case of open crack for which large thermal resistances are expected). If ones remembers conduction heat transfer, in permanent regime the following equation applies [9, chap. 3]:

$$
q=k S\left(T_{1}-T_{2}\right)
$$

where $\mathrm{q}$ in $[\mathrm{W}]$ is the rate of heat transferred from one surface at temperature $T_{1}$ to another surface at temperature $T 2$ and $S$ is the conduction shape factor [m] which depends on the particular geometry used. Moreover, taking an electrical analogy, the crack effect becomes even more evident:

heat transfer side $\leftrightarrow$ electrical side

$$
q=\frac{\Delta T}{R_{t h}} \leftrightarrow \quad i=\frac{\Delta V}{R}
$$

where i, $\Delta V$ and $R$ stand respectively for the current in Amperes $[\mathrm{A}]$, the voltage difference in Volt [V] and the electrical resistance in Ohm [ $\Omega]$. The electrical side of Eq. 2 is known as the Ohm's Law. It follows Eq. 2 that units of $R_{\text {th }}$ are in [ $\left.{ }^{\circ} \mathrm{C} / \mathrm{W}\right]$. Thermal problems can be converted to their electrical analogue for which practical methods are deployed for solving. For example, if a crack induces a ther- 


\section{http://dx.doi.org/10.21611/qirt.2004.081}

mal resistance $R_{1}$, we will thus have a drop of temperature $\Delta T=q R_{1}$ and obviously more important is the crack, greater will be the temperature drop across the crack.

Such a basic theory was adopted for the problem discussed in the previous section. Heat flow q was made propagating over the SC surface thus causing a temperature drop due to the thermal resistance of the crack. Pointing an IR camera made possible detection of the temperature drop and thus localization of the crack. Interestingly, such propagation can be performed either with a "warm" or "cold" thermal front. Various image processing techniques are possible to enhance cracks and also enable their automatic detection.

\section{Cracks}

As discussed previously, presence of cracks can be disastrous in PV cells. To test the IRT approach, fully open cracks can be generated easily by breaking the PV cells. Other kind of cracks are difficult to generate and since they are difficult/impossible to detect on the production line, availability of PV specimens with such cracks is in fact not really possible [10].

In order to access specimens with micro-cracks, laser ablation was thus relied on. A Ti-Sapphire femto-second chirped pulse amplification ablation laser was thus used to make up calibrated micro-cracks of different lengths and depths on the specimens: 12 to $145 \mu \mathrm{m}$ depth. However this technique provides triangular-shaped micro-cracks with large mouths at the surface and tiny tips. For example, the deepest crack was: $160 \mu \mathrm{m}$ depth, with width of $120 \mu \mathrm{m}$ and $20 \mu \mathrm{m}$ respectively at surface and crack tip [11]. All experiments were performed on specimens on which such micro-cracks were generated either on front or back faces.
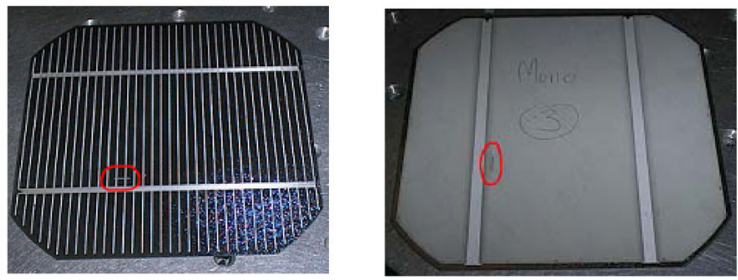

Fig. 2: Visible picture of a micro-cracked solar cell (left front and right bottom).

As noted, reflection on PV cells is high and thus emissivity is relatively low. As it is known, emissivity is the surface property related to the thermal emission [9]. In order to perform IR measurement of a surface, its emissivity must be high, that is this surface should emit enough energy. However, it was noted the microcracks were well detected by IR NDT, it is suspected the triangular-shape of the cracks can be account for a kind of micro-cavity which could be associated to a blackbody thus increasing locally the PV emissivity. It is thus not known at this stage how such micro-cracks are representative of actual micro-cracks [10]. 


\section{http://dx.doi.org/10.21611/qirt.2004.081}

\section{Thermoelectric stimulation}

Solid state heat pumps have been known since the discovery of the Peltier effect in 1834. With the development of semiconductor thermocouple materials thermoelectric modules became available. Many junctions connected in series electrically and in parallel thermally, are integrated into modules which are then packaged between metallized ceramic plates yielding to electrical insulation and thermal conduction with high mechanical strength in compression. Typical modules contain up to an hundred modules and even more. Modules can be mounted in parallel to increase the heat transfer effect or can be stacked in multistage cascades to achieve high differential temperatures [12].

Thermoelectric modules (TEM) $n^{\circ} \mathrm{CP}$ 0.8-63-06L from Melcor were used in the present project. Their size is $12 \mathrm{~mm} \times 25 \mathrm{~mm} \times 3.4 \mathrm{~mm}(\mathrm{WxLxH})$. At full power of $7.6 \mathrm{~V}$ and $2.1 \mathrm{~A}$, a maximum temperature of $67^{\circ} \mathrm{C}$ differential is reached. In all experiments, the settings were fixed at $7 \mathrm{~V}, 1.9 \mathrm{~A}$. The TEM were mounted on a thick Al base with thermal grease in order to dissipate the energy transferred from the module.
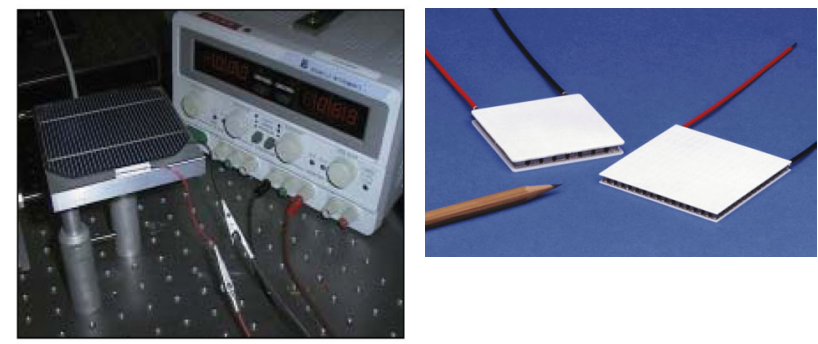

Fig. 3: Picture of experimental rig and TEM from Melcor at right.

\section{Experiments}

Various tests were conducted using TEM:

- a single TEM generating a hot thermal front (Figure 3 left).

- a single TEM generating a cold thermal front (Figure 3 right). Interestingly, reversing the power at the TEM reverses also the thermal transfer.

- two TEMs generating respectively hot on one side and cold on the other side thermal fronts.

- two TEMs generating respectively hot and cold thermal fronts on the each side of the PV cell.

- two TEMs generating respectively hot and cold thermal fronts perpendicularly on the sides of the PV cell.

- two TEMs generating respectively hot or cold thermal fronts perpendicularly on the sides of the PV cell. 


\section{http://dx.doi.org/10.21611/qirt.2004.081}

These tests indicated raw thermal imaging already allow to detect microcrack quite reliably through TEM thermal stimulation. Automatic micro-crack detection is possible if this technique is coupled to appropriate image processing [11].
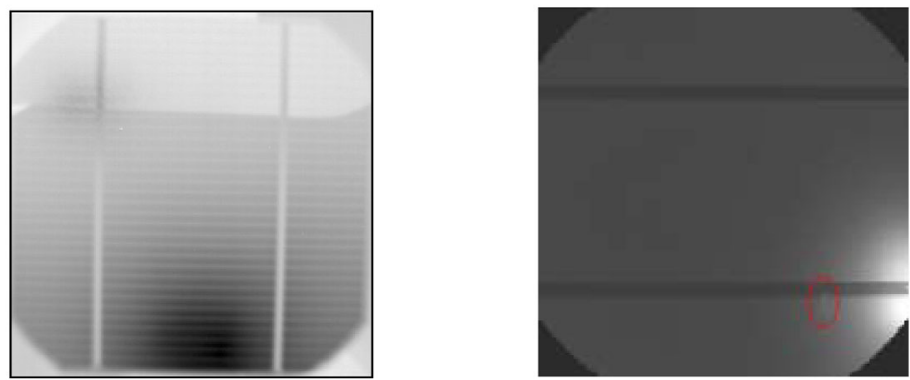

Fig. 4: TEM stimulation of PV cells. Left: a TEM generating a hot thermal front (through crack). Right: a single TEM generating a cold thermal front (micro-crack circled).

Moreover, the many tests conducted allowed us to draw the optimal testing rig as depicted on Figure 4. In this configuration, the steps for thermal stimulation would be as follow:

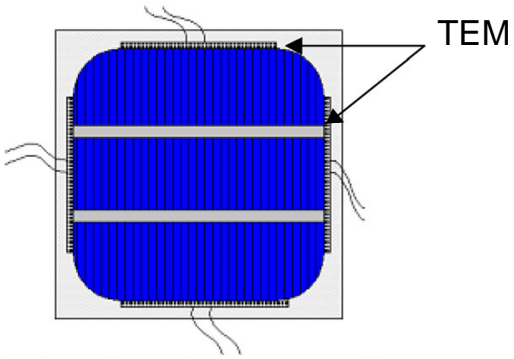

Fig. 5: Ideal experimental rig to test $\mathrm{PV}$ cells for micro-cracks:

the TEM are located on each side of the cell.

$1^{\circ}$ - power opposed TEM with same polarity for about 7 to $10 \mathrm{~s}$ so that the hot thermal fronts meet at the cell center.

$2^{\circ}$ - unplug the powered TEM and power - for the same duration - the two others with reverse polarity with respect to step $1^{\circ}$.

$3^{\circ}$ - observe the thermal fronts with an IR camera during the whole experiment. The fact two thermal front are generated perpendicularly allow to detect micro-cracks of any orientation on the PV cell, in particular those parallel (or perpendicular) to the PV edges.

Observation period (of about $20 \mathrm{~s}$ ) could be reduced if more efficient TEM are used. Since propagation on cell surface is relatively slow, an IR image acquisition rate of about $2 \mathrm{~Hz}$ (for a total of 40 images to record) is enough. 


\section{Conclusions}

In this paper, a technique was discussed to detect micro-cracks in PV cells. The technique is based on thermoelectric (TE) thermal stimulation of the PV cell so that a lateral thermal front circulates on the cell surface. Observation is performed by visualization of the thermal front propagation with an IR camera. The method was validated on artificial micro-crack of different sizes. This method of stimulation is original. If an image processing step is added, automatic micro-crack detection can be achieved.

\section{Acknowledgement}

Support of Po K. Lau and Sean O'Donoghue from ICP Global Technologies Inc. Montréal is acknowledged.

\section{REFERENCES}

[1] O. Breitenstein, M. Langenkamp, K.R. Mclntosh, C.B. Honsberg, M. Rinio, "Localization of shunts across the floating junction of DSBC solar cells by lockin thermography, Proc. IEEE, p. 124-127, 2000.

[2] Micahel Bail, Jörg Kentsch, Rolf Brendel, and Max Schulz, "Lifetime mapping of si wafers by an infrared camera,"Proc. IEEE, p. 99-103, 2000.

[3] John H. Wohlgemuth, Mark Conway and David H. Meakin, "Reliability and performance testing of photovoltaic modules" Proc. IEEE, p. 1483-1486, 2000.

[4] M.A. Quintana, D.L. King, F.M. Hosking, J.A. Kratochvil, R.W. Johnson, B.R. Hansen, "Diagnostic analysis of silicon photovoltaic modules after 20-year field exposure," Proc. IEEE, p. 1420-1423, 2000.

[5] ASNT Handbook on NDT Series (www.asnt.org).

[6] W. Gross, J. Zettner, H. Scheuerpflug, Th. Hierl, M. Schulz, and F. Karg, "Thermosensoric Localization Of Defects In Cis Solar Modules," Proc. 26th PVSC, p. 551-554, 1997.

[7] D.L. King, J.A. Kratochvill, M.A. Quintana, T.J. McMahon, "Applications for infrared imaging equipment in photovoltaic cell, module, and system testing," Proc. IEEE, p. 1487-1490, 2000.

[8] M. Pilla, F. Galmiche, X. Maldague, "Thermographic Inspection of Cracked Solar Cells," SPIE Proc. Thermosense XXIV (SPIE: Society of Photo-Optical Instrumentation Engineers), 4710: 699-703, Orlando, X. Maldague, A. Rozlosnik eds., 2002.

[9] X. Maldague, Theory and Practice of Infrared Thermography for Nondestructive Evaluation, New York, John Wiley pub., 2001, 684 p.

[10] H.-M. Voigt, VISOLAR - Esprit HPCN PST Activity 28514 (www.ttnt.de/visolar/ pv42.htm).

[11] L. St-Laurent, M. Genest, C. Simon, "Détection de fissures dans les cellules photovoltaïques," Rapport Laboratoire de Vision et Systèmes Numériques, Université Laval, 46 p., 2003.

[12] paragraph adapted from: www.melcor.com/history.htm. 